\title{
"Leadership in the Cross-Cultural Context" Analyze of Rational Theories and Aspects of Leader Role in Long Term Characterized. The Observation of Behavior Effects in Albania
}

\author{
Prof Ass Dr. Alba Robert Dumi ${ }^{1}$ \\ Ma Zamira Sinaj \\ 'Prof. As. Dr. Dean of Graduated School'Ismail Qemali" \\ Vlora University Albania, Management Department \\ Management Department, Economy Faculty, Tirana University \\ Email:besi.alba@yahoo.com \\ ${ }^{2}$ Mangement Department, Vlora University Albania, \\ Emailizsinaj@yahoo.com
}

Doi:10.5901/ajis/2012.v2n1p59

\begin{abstract}
This paper research overview of the leader behavior literature highlighted the fact that there are inconsistent relationships between the behaviors that leaders engage in and the effects of these behaviors on member attitudes, behavior, and group effectiveness. While these inconsistent observations can be frustrating they underscore two very important facts. The behaviors are important as witnessed by their occasionally significant relationship with follower attitudes and behavior. Second, the observation that these behaviors do not always produce significant and positive effects suggests that something else is transpiring such that in one situation the particular leader behavior produces significant effects and in another situation that behavior is relatively unimportant. The question that these observations raise is. What effects do situational differences produce in the leader-follower relationship? Many decades ago Ralph S (I948) stated that "the qualities characteristics, and skills required in a leader are determined to a large extent by the demands of the situation in which he [she] is to function as a leader" chapter 8 provides an understanding of situational differences in the leadership process. If team members know for example, exactly what needs to be done, when, who and why, it is unlikely that initiating structure will prove to be needed or be effective if use. In contrast, when team members are operating under conditions of high levels of uncertainty-not knowing what, when or how to execute the task-a leader who is capable of initiating some structure will make a meaningful contribution. In this paper we are focus in leader role and in the influences of rationality behavior: The simple theme of this paper is might well be "different strokes for different folks" and/or "different strokes for the same folks at different points in time". Put more directly, as conditions change, so do the leadership needs that are created and the leader behaviors that will prove effective. We are trying to analyze the effects of using different hypotheses in some definitions of leadership theories, the implementation of effects of leader behavior in organizations.
\end{abstract}

Key words: Influence of leader, values, ideals, aspirations, emotions, rational theories.

\section{Hypotheses and rationale influences theory}

Hypotheses about the use and effectiveness of each tactic for influencing target task commitment are presented next, along with a rationale for each of fourth hypotheses, that in this paper research are in our focus study and in based on our preliminary model and on prior research. Formal hypotheses were not made for ratings of a manager's overall effectiveness because this criterion can be affected by many 
things besides a manager's use of influence tactics. Rational persuasion involves the use of logical arguments and factual information to convince a target that the agent's request or proposal is feasible and consistent with shared objectives (Eagly \& Chaiken 1984). This is a flexible tactic that can be used for influence attempts in any direction. Nevertheless, rational persuasion is likely to be used more in an upward direction that in other directions, because in an upward direction a manager is limited by a weaker power base and role expectations that discourage the use of some tactics (see discussion of other hypotheses).

\section{I.I Introduction}

Inspirational appeals use the target's values, ideals, aspirations, and emotions as a basis for gaining commitment to a request or proposal (Yukl 1990). Inspirational appeals appear feasible for influence attempts made in any direction, but this tactic is especially appropriate for gaining the commitment of someone to work on a new task or project. Influence attempts and involving task assignments occur most often in a downward direction and least often in an upward direction (ErezI986, Kipnis 1980, Yukl \& Falbe, 1990)

Thus managers have more opportunity to use inspirational appeals with subordinates than with peers or superiors. In the only prior study to examine directional differences for inspirational appeals, (Yukl and Falbe (1990) found that inspirational appeals were used more in downward influence attempts than in lateral or upward influence attempts.

\section{Literature Review and Hypotheses}

Agents reported greater use of this tactic in upward influence attempts, but directional differences were not found for targets. Results for the consequences of using rational persuasion have been inconsistent also. In the questionnaire study by Kipnis and Sshmidt (1988) managers who received the highest performance ratings had a profile in which rational persuasion was the dominant tactic for upward influence attempts. However rational persuasion was not related to successful upward influence in the questionnaire study by Mowday (1978). Likewise tactics involving aspects of rational persuasion were not related to outcome success in the four critical incident studies described.

Graph I. The cycle of rationality developments of hypotheses,

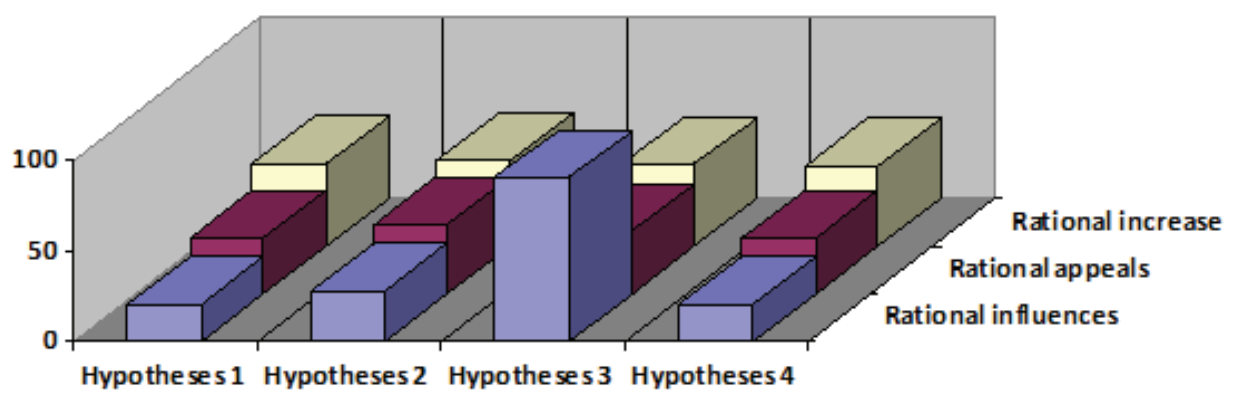

Source: Mowday theory concepts 1978

HypothesisIa. Rational persuasion is used more in an upward direction than in a downward or lateral direction. 
HypothesisIb. Rational persuasion increases task commitment in all three directions.

When people gain a sense of ownership of a project, strategy, or change after participating in planning how to implement it, they are likely to be more committed to making the project, strategy or change successful (Yukl 1989). This influence tactic can be used in any direction, but it appears especially appropriate in the situation in which an agent has the authority to plan a task or project but relies on the target to help implement the plans. Because authority to assign work and make changes in work procedures is mostly downward a manager probably has more opportunity to use consultation to influence subordinates than to influence peers or superiors (Yukl \& Falbe, 1990.

\section{I The variety of hypotheses and limited results.}

Only one study examined directional differences in frequency of use for consultation (Yukl \& Fable, 1990) and results were mixed. Agents reported greater use of consultation in a downward direction, but directional differences were not significant for target reports. Evidence on the likely effectiveness of consultation as an influence tactic is limited and inconsistent. Locke (1982) found that a consultation tactic (using the target as a platform to present ideas) was likely to be effective in upward incidents reported by targets, but the results were not significant for upward incidents reported by agents in that study Locke (I988).

\subsection{The significant indicators of this paper research study.}

In the study by Vroom (1988) of downward incidents reported by agents, results for consultation tactics (listening, soliciting ideas) were not significant. Indirect evidence comes from research on leadership, which finds that consultation with individual subordinates is effective for increasing decision acceptance in some situations but not in others (Vroom \& Jetton, 1988) Hypothesis2a. Inspirational appeals are used more in a downward direction than in a lateral or upward direction. Hypothesis $2 b$. Inspirational appeals increase task commitment in all three directions.

\section{Leadership and situational differences impacts.}

This paper research addresses the situation in the leadership process. The evolving leadership model from the earlier theories we suggests that the situation in part defines the leadership process and that it influences the leader and the interact role of leader with the leader's attempts to influence his or her followers. The importance of the situation has already been alluded to on numerous occasions through the first several theories. Murphy 9194I), for example noted that situations in which people find themselves create needs, and it is the nature of these needs that defines the type of leadership that best serves the group. 
Graph 2 The different defines of leadership theories,

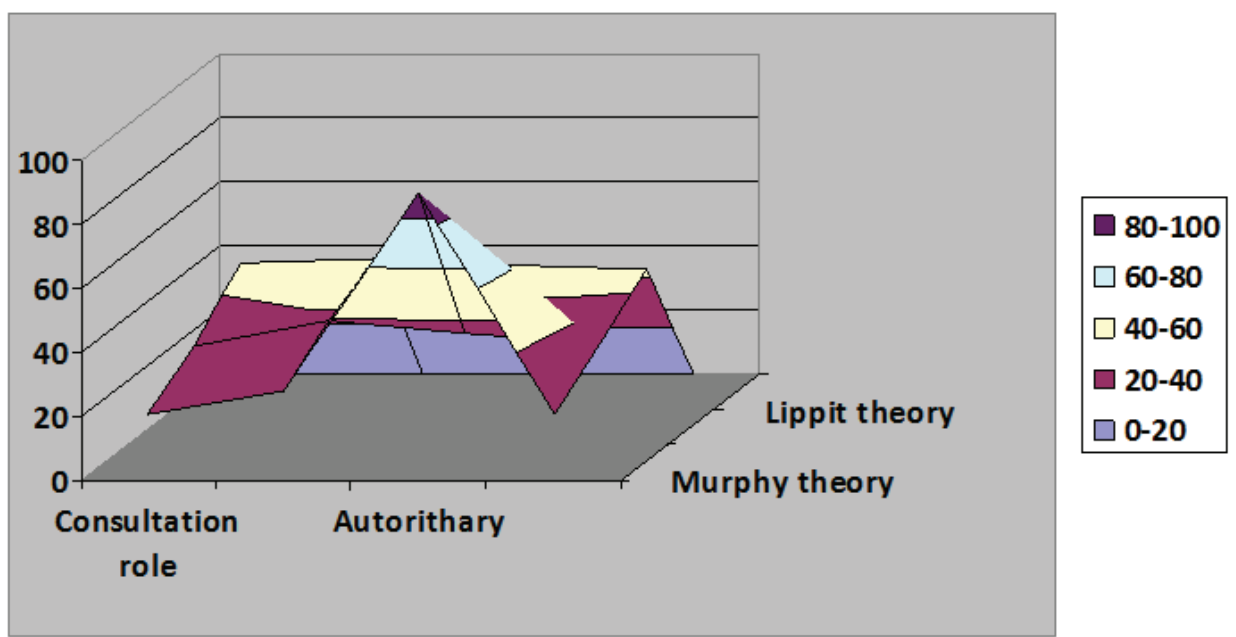

Source; IJERM Journal Nr 3, year 2012

Accordingly, Murphy theory and findings, saw leadership is a working relationship-one in which different contexts create one unique set of group needs, and a group's emerging leader is that individual who is capable of making meaningful contributions to the group. We are focus in "Hypothesis $3 \mathrm{a}$ and $3 \mathrm{~b}$ to overview in indicate of their effects. These hypotheses, helps us created the leaders modeling according Webber theory. Hypothesis3a. Consultation is used more in a downward direction that in a lateral or upward direction.

Hypothesis $3 b$. Consultation increases task commitment in all three directions. Three keys questions that will be addressed are:

- Does the situation in which the leader and follower are embedded make a difference?

- What leader behavior works and when?

- What is the process through which the situation produces its effects

\section{I Strategic leadership models and critical leadership situations}

In Salancik and Pfeffer's (1977) strategic contingencies model of leadership, the leader is a person who brings scarce resources to assist a group of individuals in overcoming a critical problem that they face. As the problems facing a group change, their leader may also change because of his or her access to critical and scarce resources. Thus, Salancik and Pfeffer's work also serves to highlight the importance of the situation in defining leadership and the leadership process. Tab 2 shows the influences of situational leadership theory. 
Graph 3 Influences of situational propositions of leadership context with different authors theories,

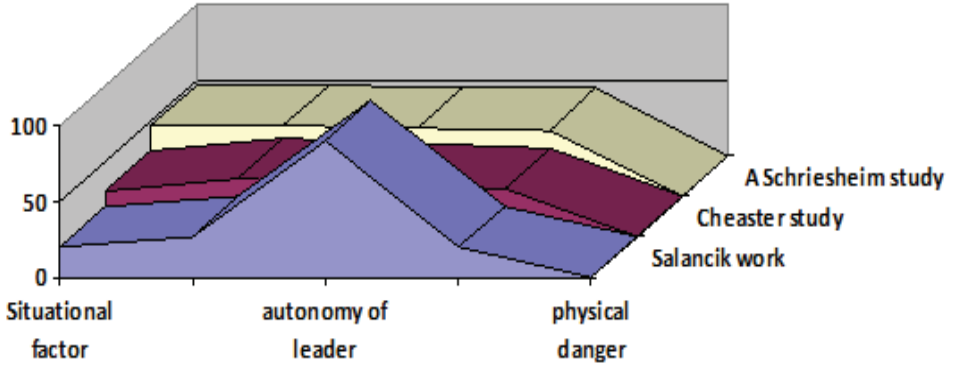

口 Salancik work

$\square$ Cheaster study

$\square$ A Schrie sheim study

Source: Leadership process, year 2008, USA

Influenced by Stogidill's (1948, 1974) reviews of the leader behaviors literature and the emerging recognition of the importance of the leadership context , Steven Kerr, Charles Murphy and Ralph Stogidill (1974), advanced a number of situational propositions linking leader of structure and consideration to a leader effectiveness. They note that accumulated evidence suggests that leader effectiveness is not always associated with those who behave in highly considerate and structuring manner. Among some of the situational factors that influence the effectiveness of leader consideration and initiating structure behavior are, for example, time urgency, amount of physical danger presence of external stress, degree of autonomy, degree of job, scope, importance, and meaningfulness of work.

\section{Methodology and Research Goal}

Design - The Multifactor Leadership Questionnaire (MLQ) was distributed to employees of a public security organization in Albania, asking them to evaluate their supervisor's style of leadership. Employees were also asked to report their perceptions of organizational politics using the scale developed by the leaders in Albania Region. In addition, supervisors provided objective evaluations of the levels of their employees' in-role performance and OCB. The intra-structure of the leadership variable was examined by exploratory factor analysis (EFA) and confirmatory factor analysis (CFA) with structural equation modeling. Two alternative models were examined: first, a model of mediation and second, a direct model with no mediation.

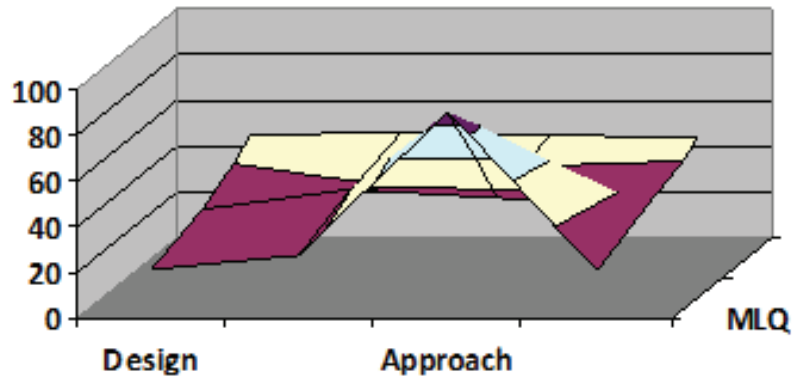

80-100
$60-80$
$40-60$
$20-40$
$0-20$


Findings - The research resulted in mixed findings that only partially support the mediating effect of organizational politics on the relationship between leadership, in-role performance and OCB. A direct relationship between leadership and performance (in-role and OCB) was also found.

This study empirically examines the impact of debt management policies on borrowing costs incurred by state governments when issuing debt in the municipal bond market. Based on positive political theory and the benefit principle of taxation, it is proposed that states that adhere to best practice debt management policies transmit signals to the credit ratings, investment community and taxpayers that the government should meet its obligations in a timely manner, resulting in lower debt costs. ${ }^{\mathrm{I}}$ The donors concurred with this assessment. IDA, starting with the I998 CAS, considered governance and institution building as one of the central planks of its intervention and identified the need to adopt and implement reforms to build an accountable and transparent state as the most important challenge facing the Government of Albania.

Hypothesis4a. Ingratiation is used more in a downward and lateral direction than in an upward direction.

Hypothesis $4 b$. Ingratiation has a stronger positive effect on task commitment in a downward and lateral direction that in an upward direction.

Robert House (197I) contends that leader effectiveness is most appropriately examined in terms of the leader's impact upon the performance of his or her followers. In the first reading in this chapter, House and Terence Mitchell (1974) assert that a leader's behavior will be motivational and subsequently have an impact upon the attitudes and performance behavior of the follower to the extent that it makes the satisfaction of a subordinate's needs contingent upon his or her performance.

\section{I Foreign experiences of organizational behavior}

The vast majority of the contemporary scholarship directed toward leaders and the leadership process has been conducted in North America and Western Europe.Observing the volume of theory and research that has emerged around the concept of leadership over the past several decades Meindl A and his colleagues to suggest that "we may have developed a highly romanticized, heroic view of leadership. Leaders have come to occupy center stage in organizational life. We use leaders in our attempts to make sense of organizational behavior. They are seen as the key to organizational success and profitability they are credited for organizational competitiveness, and they are the focus of blame in the face of organizational failure.

A driving question in this stream of inquiry asks whether or not the effectiveness of leadership (leader behavior) is culture-specific.

This larger-than-life role ascribed to leaders and the Western romanticized affair with successful leaders raises questions as to how representative our understanding of leadership is across other cultures. That is, do leadership theory and research results generalize from one culture to the next? Research into culture has generally addressed two questions. First there has been an interest in whether or not there are significant leadership differences across cultures. Thus, it might be asked whether culture gives rise to leadership differences. The second questions treats culture, as a key contextual variable.

\subsection{Hofstede theory and five value dimensions of cultural differences in leader identification.}

Geert and Hofstede's (1993, 1980) work provides a useful framework for the identification and

${ }^{1}$ Donors and government investments, IDA 
classification of cultural differences. Hofstede's work spans I8 years, involving more than I50000 people and cutting across 60 countries. He identified five value dimensions that can be employed to explain differences in leadership (leader traits and behaviors) that might cut across cultures. These value frameworks consist of:

\section{- Individualism-collectivism}

Individualism as a mental set in which people see themselves first as individuals and believe their own interests and values take priority (Canada, Great Britain, and the United States).

Collectivism reflects the feeling that the group or society should receive priority (Hong Kong, Greece, Japan and Mexico).

The self-assessment appearing at the end of this chapter opener provides you with the opportunity to profile yourself in terms of your individualistic / collectivistic values (general guiding principles for behaviors).

\section{- Power Distance}

Power distance reflects the extent to which members of a social system accept the notion that members have different levels of power.

High power distance suggests that leaders make decisions simply because they are the leader (France, Japan, Spain and Mexico).

Low power distance suggests that social system members do not automatically acknowledge the power of a hierarchy (Germany, Israel, Ireland, and the United States).

\section{- Uncertainty Avoidance}

Low uncertainty avoidance is reflected by people who accept the unknown and tolerate risk and unconventional behavior (Australia, Canada, and the United States).

High uncertainty avoidance is characterized by people who want predictable and certain futures (Argentina, Israel, Japan and Italy).

\section{- Masculinity-Femininity}

Masculinity refers to an emphasis that gets placed on assertiveness and the acquisition of money and material objects, coupled with a de-emphasis on caring for others (Italy and Japan).

Femininity places an emphasis upon personal relationships, a concern for others and a high quality of life (Denmark and Sweden).

\section{- Time orientation}

Tab 4 Long term characterized and short term perspectives.

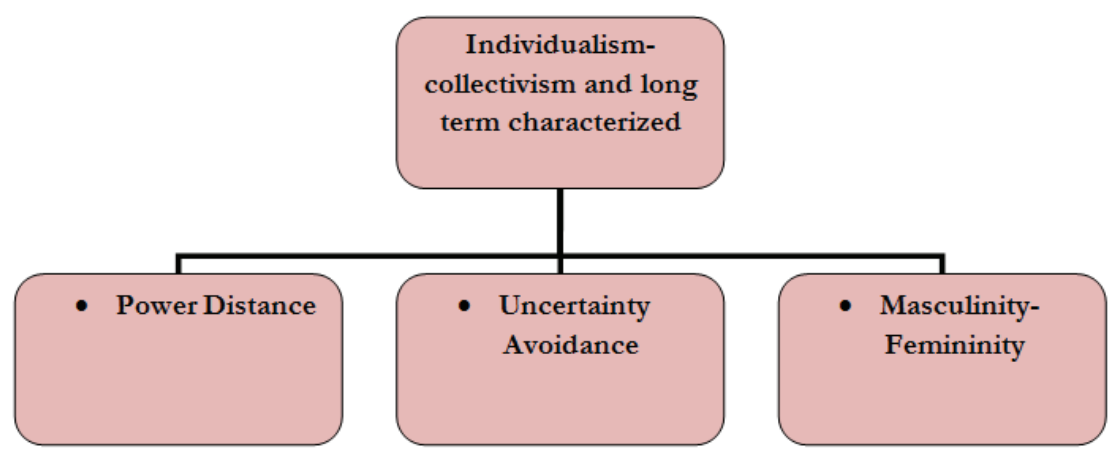

Source: Dumi A, MJSS, Vol 3 Nr 32012 
Long-term orientation is characterized by a long-range perspective coupled with a concern for thrift and weak expectations for quick returns on investments (Pacific Rim countries).

Short-term orientation is characterized by a long-range perspective coupled with a concern for thrift and weak expectations for quick returns on investments (Pacific Rim countries).

\subsection{The strategic planning of e-learning in the Albania}

E-Learning is gaining significant interest in distance education, including university and other. It also get a special importance in terms of exchanges of experiences between different institutions within and outside the country. Despite the distance people already have the opportunity to learn from others, or used in any other time and place that they are. These advantages are powered by technological developments, developments that require a generation as qualified to be adopted in time with the rapid technologic evolutions. The advantages of using e-learning are related to the degree of qualification of the generation which live in an era of rapid technological change. Despite the rapid technological development in many countries there are benefits from the use of e-learning or there are benefits that are not at levels as it's required.

\section{SWOT Analysis and E-learning considerations}

E-learning will be consider as one of the new business that requires the implementation of a modern infrastructure for the needs of customers. In determination of the needs customers there is always a question, which is necessary by enterprises in the e-learning to identify the application, create and determine its size. Above it is explained that the concept of e-learning is very broad, there is only about distance learning, but we have included this concept, different meanings, referring to the electronics companies in all markets. We identify the opportunities and threats, strengths and weaknesses, and their impact on the choice of strategic alternatives are summarized SWOT analysis below.

Table I: SWOT analysis by powers, weaknesses, opportunities and threats for the study of internal and external context were identified four strategies

\begin{tabular}{|l|l|l|}
\hline Internal factors & $\begin{array}{l}\text { Strengths } \\
\text { I. qualified human } \\
\text { resources. } \\
\text { 2. Internal logistics }\end{array}$ & $\begin{array}{l}\text { Weeknesses } \\
\text { I.Experiences } \\
\text { 2. Provision of necessary financial funds. } \\
\text { 3. Marketing }\end{array}$ \\
\hline Opportunity: & Strategies: & Strategies: \\
\hline $\begin{array}{l}\text { I. The increase of Internet } \\
\text { users market }\end{array}$ & $\begin{array}{l}\text { I.The entry strategy and } \\
\text { market growth } \\
\text { prosperity }\end{array}$ & $\begin{array}{l}\text { 2.The strategy of strategic alliances. (To } \\
\text { provide the necessary funds and } \\
\text { organization of marketing campaigns for } \\
\text { the presentation of products and services to } \\
\text { be offered on the market) } \\
\begin{array}{l}\text { 3.Fulfillments of legal and } \\
\text { political vacuum } \\
\text { 4. Demographic structure } \\
\text { (domination by young people) }\end{array}\end{array}$ \\
\hline
\end{tabular}




\begin{tabular}{l|l|l|}
\hline $\begin{array}{l}\text { Threats: } \\
\begin{array}{l}\text { I. The rapid technological } \\
\text { changes }\end{array}\end{array}$ & $\begin{array}{l}\text { 3.Outsourcing strategy } \\
\text { (some services) }\end{array}$ & $\begin{array}{l}4 . \text { Strategy and strategic alliances of } \\
\text { "outsourcing" } \\
\text { (Some services) } \\
\text { technological changes }\end{array}$ \\
\hline
\end{tabular}

\section{I The strategic alternatives of this study}

In the SWOT analysis by powers, weaknesses, opportunities and threats for the study of internal and external context were identified four strategies are:

- $\quad$ strategy of market entry and growth

- strategy strategic alliances

- strategy of the outsourcing of some services.

- strategy and alliances of "outsourcing" of some services

\subsection{The choice of strategic alternatives}

The strategies described above were the results of the SWOT analysis. But among the strategies mentioned above as the best strategy taking into account the environmental opportunities and threats external and internal potential and highlighted during the analysis it is estimated: The entry strategy and market growth. Normally the choice of alternatives can not be considered easy, because if he makes reference to the SWOT analysis, note that for each alternative is found threats and weaknesses. But in choosing this alternative strategy is thought achievement of the mission, the external environment and is adapted activity cycle of e-learning, in which they have considered the business cycle of preparing to enter the business of e-learning, and thinking about market growth.

Another reason for the choice of entry and growth strategy in the market compared to others strategies, which calls for the alliance without getting into a market is not an easy process. Once that others can look to slice alliances entered into a new and unfamiliar business. While outsourcing observed is more acceptable and more accessible, such as through outsourcing organization creates the possibility of using the services, which can not perform better than others or could not be performed

\section{Findings}

The first reading in this paper was written by Hofstede. In this reading Hofstede discusses differences in management as they exist around the globe. His writings provide us with insight into cross-cultural leadership differences as they relate to his value profile. In the second reading in this paper Peter W. and his colleagues John P, Hibino, Jin Lee, and A Bautista (1977) look at commonalities and differences in effective leadership processes across a set of Western and Asian countries. Dorfman A find that three leader behaviors (supportive, contingent reward and charismatic) appear across different cultural settings, while three behaviors (directive, participative and contingent punishment) appears to be culturally specific in terms of their linkage with leader effectiveness.

\section{Conclusions and Recommendations}

The effects of contingent punishment are unique in that this behavior has a desirable effect in only one of the Western countries (the United States) and in neither of the two Asian countries studied. Leaders who demonstrate supportive kindness and concern for followers are valued and effective in each of the 
countries studied.Leaders contingent behavior is highly effective in the more collectivism Asian culturesas it often is in Western countries. The readings in this and the preceding chapter sensitize us to the contextual factors with which leaders need to contend. Specifically Hofstede (I993) and Dorfman (1997) alert us to the fact that not all followers will have the some belief and value orientation. These differences clearly have leader and leadership implications. Our earlier reading by Murphy (I94I) suggested that leadership function of an interaction between the leader, the situation and the follower. In this paper we will focus on the follower in the leadership process. We will want to carry into those readings and understanding of the individual differences that are produced by cultures and differential belief/value systems.

\section{References}

Ashby, W.R desing for a brain. New York : wiley, 1952.

Bagozzi, R.P \& Yi, Y.Y. on the evalution of structural equation models. Journal of the academy of marketing science, I988, I6(I), 74-94.

Bass, B.M. stogdill's handbook of leadership: a survery of theory in research. New York : free press, I98I.

Bass, B.M. bass and stogdill's handbook of leadership. Theory, research and managerial application ( $3^{\text {rd }} \mathrm{ed}$.). New York : Free Press, 1990.

Blake, R.R \& Mounton, J.S. the managerial grid. Houston, TX: Gulf, I964.

Bowers, D.G \& Seashore, S.E. predicting organizational effectiveness with a four-factor theory of leadership. Administrative Science Quarterly, I966, II, I38-263.

Carmines, E.G \& Maciver, J.P. analyzing models with unobserved variables: Analysis of covariance structures. In G.W. Bohrsted and E.F. Borgatta. Social measurement: current issues. Newbury Park, CA: Sage, I98I.

Conger, J.A. the dark side of leadership. Organizational Dynamics, I993, 2I, 46-58.

Dansereau, F...Graen, G \& Haga, W.J. A vertical dyad linkage approach to leadership within formal organizations: a longitudinal investigation of the function-making process. Organizational Behavior and Human Performance. 1975, I3(I), 46-78.

Dobbins, G.H \& Platz, S.J. sex differences in leadership: How real are they? Academy of Management Review, I986, II(I), II8-I27.

Denison, D.R. Hooijberg, R \& Quinn, R.E.Paradox and performance: a theory of behavioral complexity in managerial leadership. Organization Science. 6(5), 524-540.

Dumi A., Kiser I., and Karakushi A., (2012) Oriental Policies and Investment Prospects Increasing the Economic Development Capacity in Republic of Kosovo, in Mediterranean Journal of Social Sciences Vol 3 No 3 September 20I2, doi:I0.5901/mjss.2012.v2n3p95

Falbe, C.M \& Yukl, G.Consequences for managers of using single influence tactics and combinations of tactics. Academy of Management Journal, 1992, 35(3), 638-652.

Fiedler, F.E. a theory of leadership effectiveness. New York: McGraw-Hill, 1967.

Gillespie, H.R. An investigation of current management/leadership styles of manufacturing executives in American industry. Dissertation Abstracts International, 1980I, 4I(7a), 3177.

Harris, T.G. the post-capitalist executive: an interview with Peter F.Drucker. Harvard business review, 1993, 7I, II4-I22.

Hart, S.L \& Quinn, R.E. Roles executives play: CEOs, behavioral complexity, and firm performance. Human Relations, 1993, 46(5), 543-574.

Hersey, P \& Blanchart, K.H. Management of organizational behavior: utilizing human resource (4 $4^{\text {th }}$, ed). Englewood Cliffs, NJ: Prentice-Hall, I982.

Hooijberg, R...,\& Quinn, R.E. Behavioral complexity and the development of effective managers. In R.L. Phillips and J.G.Hunt (eds), strategic management: A multi organizational -levels perspective. New York: Quorum, 1992.

House, R.J. A path-goal theory of leader effectiveness. Administrative Science Quarterly, I97I, I6, 32I-338.

House, R.J \& Mitchell, T.R. Path -goal theory of leadership. Contemporary Business, I974, 3(Fall), 8I-98.

Howell, J.M \& Higgins, C.A. Champions of technology. Administrative Science Quarterly, 1990, 35, 3I7-34I. 
Joreskog, K.G \& Sorbom, D. Liserel 7:User's reference guide. Mooresville, IN:Scientific Software, 1989.

Kanter, R.M. the new managerial work. Harvard Business Review, 1989 (November-December).

Katz, D.A \& Zaccaro, S.J. An estimate of variance due to traits in leadership. Journal of Applied Psychology, I983, 68(4), 678-685.

Kester, F \& Wollenberg, A.L. van den. Modulair system methodenleer Quasi experimenteel design. Vakgroep Mathematische Psychologie, Psychologisch Laboratorium, Nijmegen, 1986.

Kipnis, D \& Schmidt, S.Upward influence styles: Relationship with performance evolution, salary, and stress. Administrative Science Quarterly, 1988, 33, 528-402.

Kotter, J.P. the general managers. New York: Free Press, 1982.

Lieberman, S. the effects of changes in roles on the attitudes of role occupants. Human Relations, 1956, 9, 385402.

Luthans, F \& Lockwood, D.L. Toward an observation system for measuring leader behavior in natural settings. In J.G. Hunt, D. Hosking, C.A > Schriesheim, and R.Steward (eds), Leaders and managers: international perspectives on managerial behavior and leadership. New York : Pergamon Press, 1984.

Mintzberg, H. The nature of managerial work. New York: Harper and row, 1973

Morse, J.J \& Wagner, F.R. Measuring the process of managerial effectiveness. Academy of Management Journal, I978, 2I, 23-35.

Park, R.E. behind our masks. Survey, I926, 56, I35-I39.

Pinder, C, Pinto, P.R \& England, G.w. Behavioral Style and Personal Characteristics of Managers. Technical report, University of Minnesota, Center for the study of organizational performance and human effectiveness, Mineapolis, 1973.

Quinn, R.E. Beyond rational management. Mastering the paradoxes and competing demands of high performance. San Francisco: Jossey-Bass, I988.

Quinn, R.E. Spreitzer, G.M \& Hart, S.Challenging the assumptions of bipolarity: interpenetration and managerial effectiveness. In S.Srivastva and R. Fry (eds). Executive continuity. San Francisco, CA: Jossey-Bass, I99I.

Schlenker, B.R. Impression management: the self-concept, social identity and interpersonal relations.Monterey,CA: Brooks/Cole Publishing Company, 1980.

Staw, B.M \& Ross, J. Journal of Applied Psychology, I980, 65(3), 249-260.

Stogdill, R.M. personal factors associated with leadership: A survey of the literature. Journal of psychology, I948/, 25, 35-7I.

Van Fleet, D.D \& Yukl, G.A. military leadership: an organizational behavior perspective. Greenwich, CT: JAI Press, 1986.

Vroom, V.H \& Yetton, E.W. Leadership and decision making. Pittsburgh University Press, I973.

Wheaton, B. Assesment of fit in overidentified models with latent variables. In J.s. Long (ed), Common problems/propers solutions: Avoiding error in quantitative research. Beverly Hills, CA: Sage, I988.

Yukl, G.A. A New Taxonomy for Intergrating Diverse Perspectives On Managerial Behavior. Paper presented at the American Psychological Association meeting, New York, 1987.

Yukl, G.A. leadership in organization. Englewood Cliffs, NJ: Prentice-Hall, I989. (a) 
